\title{
Monitoring Fusarium Crown Rot Populations in Spring Wheat Residues Using Quantitative Real-Time Polymerase Chain Reaction
}

\author{
A. C. Hogg, R. H. Johnston, J. A. Johnston, L. Klouser, K. D. Kephart, and A. T. Dyer
}

First, second, third, fourth, and sixth authors: Department of Plant Sciences and Plant Pathology, Montana State University, Bozeman 597173150; and fifth author: Department of Research Centers, Southern Agricultural Research Center, Montana State University, Huntley 59037.

Accepted for publication 23 September 2009.

\begin{abstract}
Hogg, A. C., Johnston, R. H., Johnston, J. A., Klouser, L., Kephart, K. D., and Dyer, A. T. 2010. Monitoring Fusarium crown rot populations in spring wheat residues using quantitative real-time polymerase chain reaction. Phytopathology 100:49-57.

Caused by a complex of Fusarium species including $F$. culmorum, $F$. graminearum, and F. pseudograminearum, Fusarium crown rot (FCR) is an important cereal disease worldwide. For this study, Fusarium population dynamics were examined in spring wheat residues sampled from dryland field locations near Bozeman and Huntley, MT, using a quantitative real-time polymerase chain reaction (qPCR) Taqman assay that detects $F$. culmorum, $F$. graminearum, and $F$. pseudograminearum. Between August 2005 and June 2007, Fusarium populations and residue

stubble collected in August 2005 from F. pseudograminearum-inoculated plots. These populations declined rapidly over the next 8 months. Remnant Fusarium populations in inoculated stubble were stable relative to residue biomass from April 2006 until June 2007. These two phases of population dynamics were observed at both locations. Relative to inoculated stubble populations, Fusarium populations in other residue fractions and from noninoculated plots were small. In no case were FCR species observed aggressively colonizing noninfested residues based on qPCR data. These results suggest that Fusarium populations are unstable in the first few months after harvest and do not expand into noninfested wheat residues. Fusarium populations remaining after 8 months were stable for at least another 14 months in standing stubble providing significant inoculums for newly sown crops.
\end{abstract} decomposition were measured eight times for standing stubble (0 to 20 $\mathrm{cm}$ above the soil surface), lower stem (20 to $38 \mathrm{~cm}$ ), middle stem (38 to $66 \mathrm{~cm}$ ), and chaff residues. Large Fusarium populations were found in
Additional keywords: foot rot, residue-borne, survival.
Fusarium crown rot (FCR) is an important disease worldwide affecting a variety of cereal crops $(6,8,30)$. Symptoms associated with FCR in wheat (Triticum aestivum L.) include stand reductions and the rotting of root, crown, and lower stem tissues that turn a distinctive brown color. Under drought conditions, FCR symptoms intensify with severe infections resulting in the abortion of tillers and production of sterile spikelets $(6,7,42)$. In the Western United States, FCR is caused primarily by Fusarium culmorum (W.G. Smith.) Sacc., F. graminearum Schwabe, Group II, and F. pseudograminearum O'Donnell et. T. Aoki sp. nov. (37). Other pathogenic fungi such as $F$. avenaceum (Fr.:Fr.) Sacc., $F$. acuminatum Ellis \& Ever., F. equisiti (Corda) Sacc., Bipolaris sorokiniana (Sacc.) Shoemaker, and Microdochium nivale (Fr.) Samuels \& I.C. Hallett are also known to cause crown rot $(1,8,14,17,30,35,39)$. Average losses in winter wheat due to FCR have been estimated as high as $9.5 \%$ across large regions of the Pacific Northwest (38). Similar losses are likely to occur in other western states.

Across the United States, particularly in dry, semiarid climates such as Montana's, no-till farming practices have become popular because they conserve soil moisture and reduce soil erosion. Unfortunately, the adoption of no-till wheat cropping systems has also been linked to increased severity of several residue-borne diseases including FCR (27). For FCR, it has been suggested that

Corresponding author: A. T. Dyer; E-mail address: adyer@montana.edu

doi:10.1094/PHYTO-100-1-0049

(c) 2010 The American Phytopathological Society the increased disease severity is partially due to increased survival of the causal organisms under no-till and conservation tillage systems $(2,3,9,10,19,36)$. Due to the increased implementation of no-till farming practices and the economic importance of FCR, understanding Fusarium survival is essential for management of this disease.

Research on long-term survival and population dynamics of FCR species is limited. Historically, the method of enumeration available has been the isolation and culturing of targeted FCR species $(16,19,28,29)$. Labor-intensive culturing methods are complicated by many factors such as competition and antagonism from other organisms, expertise in identifying species, media selectivity, and assay sensitivity. Pereyra et al. (28) examined the survival of $F$. graminearum on decomposing wheat residues that were either buried or left on the soil surface using culturing techniques. F. graminearum colonization decreased over time in direct relationship to residue decomposition. After 2 years, buried stem residues were $99 \%$ degraded while surface residues were $75 \%$ degraded. Recovery of $F$. graminearum from buried residues was half that of surface residues. With the introduction of quantitative real-time polymerase chain reaction (qPCR), researchers have developed a number of assays to accurately quantify FCR species within an array of sample types $(5,13,31,34$, 40,41). Recently, qPCR was used to study the survival of $F$. avenaceum, $F$. culmorum, $F$. graminearum, and $M$. nivale in winter wheat residues (20). Köhl et al. (20) found populations of these pathogens declined significantly in stem nodes and internodes but remained stable in stubble residue over 10 months postharvest. 
Because the Köhl et al. (20) study was conducted over 10 months under relatively high moisture conditions, it may not represent the population dynamics found in the low moisture, wheat-fallow cropping systems of the Pacific Northwest and Northern Great Plains. In response to the need for accurate information in low moisture environments, this study was conducted at two locations representing typical dryland wheat producing regions of Montana. The primary goal was to establish baseline population dynamics for FCR pathogens in wheat residues under conditions typical of Montana's wheat production systems using a previously developed qPCR assay $(15,40)$. Additionally, this study provided an initial assessment of colonization of uninfested residues by FCR species during noncropping periods and the impacts that recently adopted solid-stem cultivars used for controlling wheat stem sawfly (Cephus cinctus) may have on Fusarium survival.

\section{MATERIALS AND METHODS}

Field plots and spring wheat residue samples. Spring wheat trials were established at the Montana State University (MSU) Arthur H. Post Research Farm (Bozeman, MT) and the MSUSouthern Agricultural Research Center (Huntley, MT) to examine Fusarium population dynamics in wheat residues during noncropping periods. These locations were chosen because of differences in average annual precipitation and temperature. Bozeman has a 40-year average summer temperature (June, July, and August) of $17.2^{\circ} \mathrm{C}$ and an annual rainfall of $41.4 \mathrm{~cm}$. In comparison, Huntley is hotter and drier with a 40 -year average summer temperature of $19.7^{\circ} \mathrm{C}$ and an annual rainfall of $33.7 \mathrm{~cm}$. The field site for the Bozeman plots had been left fallow for 1 year prior to planting and the field site for the Huntley plots had been out of cereal production for 3 years.

At each location, six replicated plots of the hard red spring wheat cvs. Choteau (21) and Outlook (22) were planted in a randomized complete block design. The cv. Choteau is solid stemmed while Outlook is hollow stemmed. The plots were inoculated in-furrow at planting with $5.3 \mathrm{~g} / \mathrm{m}$ row of $F$. pseudograminearum (isolate 2228) oat inoculum (24) to assure FCR disease development. A parallel trial was conducted at each site using the same overall design except that the plots were not inoculated. This parallel trial was located adjacent to the inoculated plots. Plots were sown on 2 May 2005 at Bozeman and 28 March 2005 at the Huntley location. In Bozeman, plots were eight rows by $3.0 \mathrm{~m}$, seeded on $30.5 \mathrm{~cm}$ centers. In Huntley, plots were eight rows by $4.5 \mathrm{~m}$, seeded on $38.1 \mathrm{~cm}$ centers. In Bozeman, 25-20-0 (N-P-K) fertilizer (113.4 kg/ha) was top dressed and weeds were controlled using Bronate Advanced (36\% bromoxynil $+40 \% \mathrm{MCPA}$ at 1.2 liters/ha). At the Huntley location, 11-52-0 (N-P-K) fertilizer $(113.4 \mathrm{~kg} / \mathrm{ha})$ was applied in-furrow at planting and weeds were controlled using Bronate Advanced $(36 \%$ bromoxynil + 40\% MCPA at 1.2 liters/ha) + Harmony Extra (thifensulfuron-methyl $33.33 \%+$ tribenuron-methyl $16.67 \%$ at $24.2 \mathrm{~g} / \mathrm{ha})+\mathrm{R}-11(292.8 \mathrm{ml} / \mathrm{ha})+$ AMS $(2.3 \mathrm{~kg} / \mathrm{ha})$. Weeds were controlled throughout the rest of the experiment at both locations using spot applications of RoundUp Ultra (glyphosate $41 \%$ at $2.1 \mathrm{ml} / \mathrm{liter}$ ) and manual disturbance.

Prior to harvest in mid-August, plants from an arbitrarily selected $1.2 \mathrm{~m}$ of row were pulled from each plot for biomass analysis and disease scoring. Tillers were visually scored on a 1 to 4 scale for FCR severity using previously described methods (15). Due to varying tiller numbers in the $1.2 \mathrm{~m}$ of row pulled, a disease severity index (DSI) was calculated as such: $[\{\Sigma[1(n)+$ $2(n)+3(n)+4(n)] / 4 \times($ total $n)\} \times 100]$, where $n$ is the number of tillers in each category. Additionally, the percentage of type- 4 tillers ( $100 \%$ browning of the first internode) was calculated for each plot as this measurement is also frequently used to assess FCR severity $(35,37)$. After scoring, tillers were cut into five different fractions being the stubble $(0$ to $20 \mathrm{~cm}$ above the soil surface), lower stem $(20$ to $38 \mathrm{~cm})$, middle stem $(38$ to $66 \mathrm{~cm})$, upper stem (66 cm and above), and chaff comprised of the rachis and floral tissues. The seeds were separated from the chaff using a small head thresher (Precision Machine Co., Lincoln, NE). The different plant fractions were weighed and sampled for DNA isolation and qPCR analysis. This initial sampling corresponds to the August 2005 sampling date. Because upper stem fractions made up only a small proportion of the total biomass (2 to 7\%) they were not monitored for decomposition rates and pathogen population dynamics.

After initial sampling, the middle four rows of the plots were harvested for yield using a small bundle rice binder (Mitsubishi Agricultural Machinery Co., Ltd., Tokyo, Japan) and threshed using a large Vogel thresher (Bill's Welding, Pullman, WA). After threshing, plant residue retained from each plot was separated into three groups; lower stem fractions, middle stem fractions, and chaff. For each plot, seven aliquots for each of the three residue fractions were weighed (approximately $15 \mathrm{~g}$ each) and placed in separate mesh bags $(20.3 \mathrm{~cm}$ by $30.5 \mathrm{~cm})$ that were then sewn shut and labeled. Residue bags were constructed from nylon window screening with $1.0 \mathrm{~mm}$ by $1.5 \mathrm{~mm}$ opening that retained the majority of the residue but still allowed ample contact with the soil surface. Residue bags were placed back on their respective plots (21 bags/plot) and pinned down with stainless steel hooks. Any remaining residue was spread over the plot area to mimic no-till practices. At seven time points (Oct. 2005, Apr. 2006, June 2006, Aug. 2006, Oct. 2006, Apr. 2007, and June 2007) 72 bags were collected at each location, three bags from each plot representing the three different residue fractions. Additionally, an arbitrarily selected $0.6 \mathrm{~m}$ section of row containing standing stubble residue was removed from each plot at the collection times mentioned above. Collected residue samples were washed in tap water to remove soil particles, dried at $48^{\circ} \mathrm{C}$ for $48 \mathrm{~h}$, and then weighed using an analytical balance. After weighing the residue, $120 \mathrm{mg}$ of plant tissue was removed for DNA extraction and qPCR analysis. Plant tissue from the residue bags was randomly sampled using a modified double bladed fabric razor that cut out $2 \mathrm{~mm}$ sections. For the stubble samples, plant tissues were excised from directly above the crown for all the collected stubble using the same modified razor. Over the course of the 22-month experiment, a total of 1,536 samples (8 sample times $\times 2$ locations $\times 2$ inoculum level treatments $\times$ 2 cultivars $\times 6$ plots $\times 4$ residue fractions) were analyzed with qPCR.

Plots were left fallow during the 2006 growing season. In the spring of 2007, the middle four rows of each plot were reseeded on 22 March in Huntley and 1 May in Bozeman using the same cultivars as in 2005. In Huntley, the fertilizer application was the same as 2005 but weeds were controlled using Curtail M (clopyralid 5\% + MCPA 43.4\% at 2.1 liters/ha) + Harmony Extra (thifensulfuron-methyl $33.33 \%$ + tribenuron-methyl $16.67 \%$ at $24.1 \mathrm{~g} / \mathrm{ha}$ ) + Puma (fenoxaprop-p-ethyl $11.53 \%$ at $773.0 \mathrm{ml} / \mathrm{ha}$ ) + R-11 (292.8 ml/ha) + AMS (2.3 kg/ha). Fertilizer application and weed control in Bozeman were the same as in 2005. To prevent damage, residue bags that were to be collected in April and June 2007 were removed during planting and then immediately returned to their original locations between the rows of the newly sown plots. Prior to harvest in mid-August, an arbitrarily selected $0.6 \mathrm{~m}$ section of row was removed from the new plots and tillers were scored for FCR severity and then analyzed via qPCR.

DNA extractions. DNA was isolated from plant residues using a combination of the PowerSoil DNA kit (Mo Bio Laboratories, Inc., Carlsbad, CA) and the FastDNA kit (Q-BIOgene, Irvine, $\mathrm{CA}$ ). To prevent overwhelming the initial portions of the DNA extraction with excessive plant detritus, each residue sample was separated into three 40-mg subsamples that were individually homogenized in 2-ml tubes containing two $6.5 \mathrm{~mm}$ ceramic balls, $130 \mathrm{mg}$ acid washed garnet, $740 \mu \mathrm{l}$ of Fecal bead solution 
(Mo Bio Laboratories), and $60 \mu \mathrm{l}$ of S-1 (Mo Bio Laboratories) using the Fastprep FP120 (Q-BIOgene) set on speed $6.0(\mathrm{~m} / \mathrm{s})$ for $45 \mathrm{~s}$. The homogenized subsamples were placed on ice for $5 \mathrm{~min}$ and then centrifuged for $10 \mathrm{~min}$ at $13,000 \times \mathrm{g}$. Supernatant from the three subsamples ( $150 \mu \mathrm{l}$ supernatant/subsample) was combined in a fresh tube containing $250 \mu \mathrm{l}$ of S-2 (Mo Bio Laboratories). The resulting sample, representing $120 \mathrm{mg}$ of plant tissue, was then incubated at $4{ }^{\circ} \mathrm{C}$ for $5 \mathrm{~min}$ and then centrifuged for $1 \mathrm{~min}$ at $13,000 \times g$. The supernatant was transferred to a new tube and mixed with $200 \mu$ l of S-3 (Mo Bio Laboratories). Samples were incubated and centrifuged as described in the previous step. Next, $450 \mu \mathrm{l}$ of supernatant was removed and placed in a fresh 2-ml tube containing $600 \mu \mathrm{l}$ of DNA binding matrix (Q-BIOgene). The remainder of the extraction was carried out following a previously described protocol (15). The final result of each extraction was a 60- $\mu$ l DNA sample for each 120-mg residue sample. For qPCR, these DNA samples were diluted 1:10 with $5 \mu$ of the resulting dilution being used for qPCR analysis. Thus, one may consider copy numbers reported as copy numbers per milligram of plant residue.

qPCR. To quantify populations of the FCR complex in wheat residues, a previously described qPCR assay was used $(15,40)$. This Taqman assay, based on the trichodiene synthase gene (tri5), specifically detects the three primary FCR species in Montana, $F$. culmorum, $F$. graminearum, and $F$. pseudograminearum. To monitor inhibition in the qPCR reactions (11), all undiluted DNA samples were spiked with $335 \mathrm{pg}$ of plasmid containing the $\beta$-actin gene (mjba-1) from Meloidogyne javanica (26). Real-time reactions for tri5 and mjba-1 were carried out in separate reactions and positive and negative controls were used in each qPCR run. Although trials were inoculated exclusively with $F$. pseudograminearum, the term "Fusarium populations" will be used throughout the remainder of this paper to indicate that the populations being reported include all three species in the FCR complex as per the specificity of the qPCR assay used. Fungal isolation from 320 stem samples over the duration of the experiment resulted in $94 F$. pseudograminearum isolates and no $F$. culmorum or F. graminearum isolates.

Statistical analyses. Analysis of variance (ANOVA) and regression analysis for disease ratings and Fusarium populations from the 2005 and 2007 field experiments were carried out using PROC GLM and PROC REG (Statistical Analysis System [SAS] Institute, version 9.1, Cary, NC). For both the inoculated and noninoculated trials, decomposition rates and Fusarium populations were analyzed using a multifactor analysis of variance with independent variables being location (Huntley versus Bozeman), cultivar (Choteau versus Outlook), residue fraction (stubble, lower stem, middle stem and chaff), and sampling date (eight sampling dates from harvest to early summer). These multifactor ANOVAs were performed using PROC MIXED with the REPEATED statement for repeated measures (SAS Institute). Within the REPEATED statement several covariance matrices were evaluated and 1st order autoregressive (AR [1]) was chosen because it had the lowest Akaike information criterion (AIC) score with the fewest number of covariance parameters. Inoculated plots from both locations were analyzed together as randomized complete blocks, as were the noninoculated plots. Pair-wise comparisons were made in PROC MIXED using LSMEANS and the pmix800 and DandA macros (33).

\section{RESULTS}

Biomass analysis for $\mathbf{2 0 0 5}$ field experiment. The percentage of total dried biomass was determined for the five different plant fractions at Bozeman and Huntley, MT. Significant differences in the percent biomass between locations existed in noninoculated plots for the stubble (Huntley $=14.5 \%$ versus Bozeman $=20.5 \%$; $P<0.0001)$, lower stem $($ Huntley $=29.5 \%$ versus Bozeman $=$
$31.5 \% ; P=0.0035$ ), middle stem (Huntley $=23.5 \%$ versus Bozeman $=17.5 \% ; P<0.0001)$, upper stem (Huntley $=6 \%$ versus Bozeman $=1.5 \% ; P<0.0001)$, and chaff fractions (Huntley $=$ $29 \%$ versus Bozeman $=26.5 \% ; P=0.0140)$. In the inoculated plots, there were differences between Bozeman (Fig. 1A) and
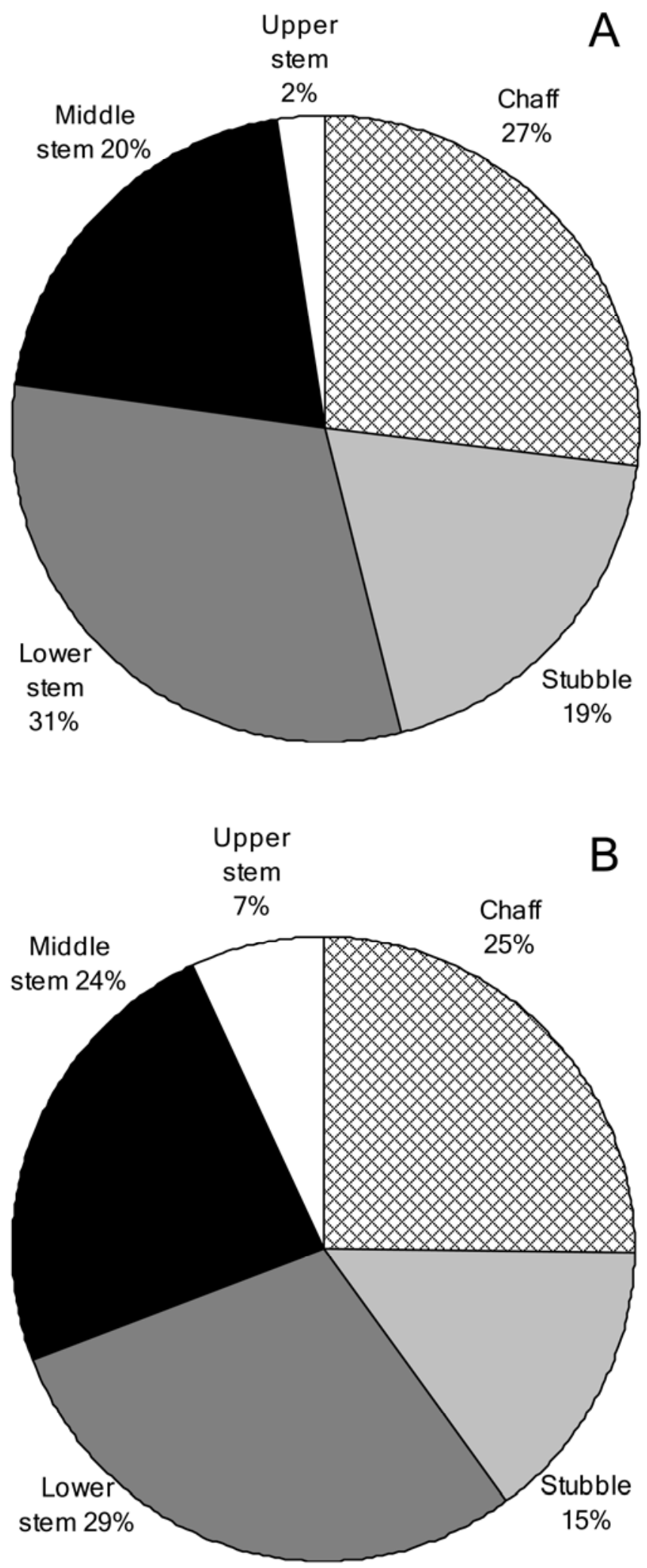

Fig. 1. Plant biomass distribution at harvest (August 2005) in Fusarium pseudograminearum inoculated spring wheat plots at A, Bozeman, MT, and B, Huntley, MT. Plants in Huntley had significantly more biomass $(P<$ 0.0001) and were taller than those in Bozeman at harvest. 
Huntley (Fig. 1B) for stubble $(P<0.0001)$, lower stem $(P=$ $0.0029)$, middle stem $(P<0.0001)$, and upper stem fractions $(P<$ $0.0001)$ but not for the chaff fraction. Although not statistically compared, biomass distribution and weight were numerically similar between noninoculated and inoculated plots. Huntley plants had more total biomass than those in Bozeman in inoculated (329 g versus $210 \mathrm{~g}$, respectively; $P<0.0001$ ) and noninoculated plots (297 g versus $153 \mathrm{~g}$, respectively; $P<0.0001)$. Differences in biomass distribution between locations (Fig. 1) reflect the crops health at each location. Plots in Huntley were taller and more vigorous then those in Bozeman. Choteau had a higher percentage of chaff residue compared with Outlook in noninoculated (29\% versus $26.5 \%$, respectively; $P=0.0078)$ and inoculated plots $(27.5 \%$ versus $24.5 \%$, respectively; $P=0.0021)$. Outlook had a higher percentage than Choteau for the middle stem fraction in noninoculated plots $(21.5 \%$ versus $19.5 \%$, respectively; $P=0.0396)$ and inoculated plots $(23 \%$ versus $21 \%$, respectively; $P<0.0001)$. In noninoculated and inoculated plots,
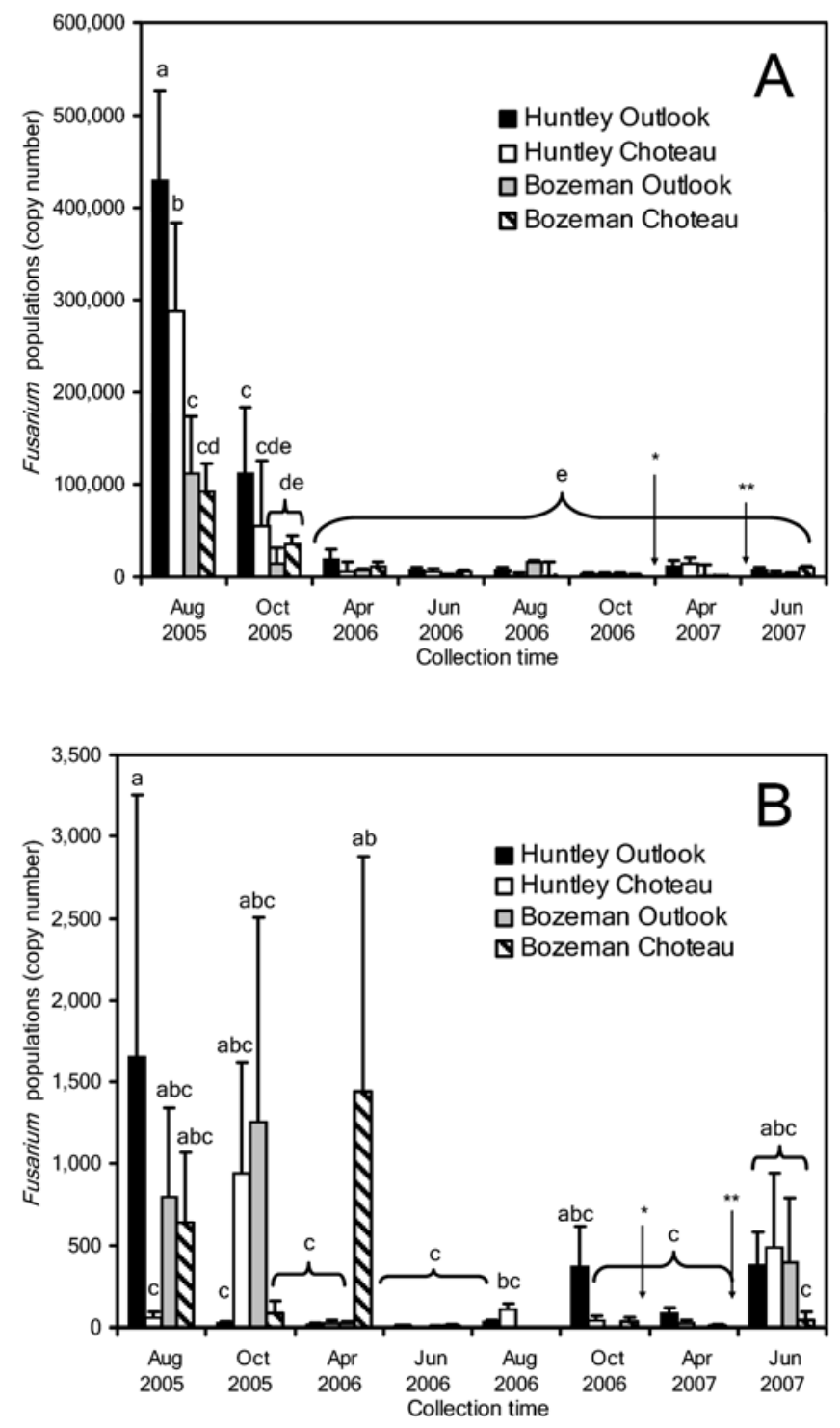

Fig. 2. Fusarium populations (F. culmorum, F. graminearum, F. pseudograminearum) in spring wheat stubble residues as measured by quantitative polymerase chain reaction from August 2005 through June 2007 for $F$. pseudograminearum $\mathbf{A}$, inoculated and $\mathbf{B}$, noninoculated plots in Bozeman and Huntley, MT. Mean separations were determined using the pmix800 macro with PROC MIXED. Copy number means with different letters are significantly different at $\alpha=0.05$ with bars representing standard errors. *, Date of replanting in Huntley and **, date of replanting in Bozeman. the stubble, lower stem, and upper stem biomasses were not significantly different between the two cultivars. Cultivars also did not differ in total biomass for noninoculated or inoculated plots.

Disease evaluations and Fusarium populations in spring wheat residues. At harvest in August 2005, more than 99\% of the detected Fusarium populations were in the stubble fraction at both locations. For this reason, Fusarium populations over time in the other residue fractions are not presented in figures. In Huntley, inoculated plots had higher Fusarium populations (mean = 359,312 copies) than Bozeman inoculated plots (mean $=101,733$ copies) $(P=0.0004)$ (Fig. 2A). Fusarium populations in Huntley noninoculated plots (mean $=710$ copies) were not significantly different than those in Bozeman (mean $=853$ copies) (Fig. 2B). There was no difference in Fusarium populations between the two cultivars for either inoculated or noninoculated plots. There was a higher DSI for inoculated plots in Huntley compared with those in Bozeman (61.1 versus 53.7; respectively; $P=0.0230$ ). Huntley noninoculated plots also had a higher DSI compared with the Bozeman noninoculated plots (61.2 and 48.0, respectively; $P<0.0001)$. Choteau had a higher DSI than Outlook $(57.5$ and 51.7, respectively; $P=0.0072$ ) in the noninoculated plots; however, there was no difference in DSI between the two cultivars in the inoculated plots (58.4 and 56.3, respectively). There was no difference in the percentage of type- 4 stems from inoculated plots at Huntley (16.8\%) and Bozeman (9.7\%). In the noninoculated plots there was a higher percentage of type- 4 stems in Huntley $(9.3 \%)$ compared to Bozeman $(1.7 \%)(P=0.0047)$. There was no difference between cultivars for the percent of type- 4 tillers in noninoculated or inoculated plots. A significant relationship existed between Fusarium populations and the percentage of type-4 tillers in inoculated plots at Bozeman $\left(r^{2}=0.34 ; P=\right.$ $0.0498)$ and Huntley $\left(r^{2}=0.35 ; P=0.0430\right)$. There was no relationship between Fusarium populations and DSI for Bozeman or Huntley plots. Regression analysis for visual disease assessments and Fusarium populations were not performed for noninoculated plots due to insufficient disease levels.

Standing stubble and residues in nylon bags were sampled over 22 months (August 2005 through June 2007) to monitor $\mathrm{Fu}$ sarium population dynamics. Fusarium populations were still detectable in moderate numbers in inoculated stubble residue at both Huntley (mean = 5,635 copies) and Bozeman $($ mean $=6,802$ copies) in June 2007, 22 months after initial harvest (Fig. 2A). In inoculated plots, Fusarium populations significantly differed over time $(P<0.0001)$, between locations $(P=0.0002)$, and between residue fractions $(P<0.0001)$. Fusarium populations in inoculated stubble residues at both Bozeman $(P<0.0001)$ and Huntley $(P<0.0001)$ significantly declined over time, with the largest population decline occurring between August 2005 and October 2005 (Fig. 2A). Populations in the stubble did not significantly change from April 2006 through to June 2007 (Fig. 2A; $\alpha=0.05$ ). For the other three residue fractions, no significant change in Fusarium populations was observed over the 22 months with populations ranging from 0 to 800 copies (data not shown). There was also no significant difference between the two cultivars in regards to Fusarium populations over time in inoculated plots for all residue fractions. Fusarium populations in Huntley inoculated stubble residues were higher over time than those in Bozeman stubble residues $(P<0.0001)$ (Fig. $2 \mathrm{~A})$. There was no significant difference in Fusarium populations between the two locations for the other residue fractions.

In noninoculated plots, Fusarium populations only significantly differed for residue fraction $(P=0.0002)$ over the 22 months. Fusarium populations significantly declined over time in Bozeman $(P<0.0001)$ and Huntley stubble residues $(P<0.0001)$ (Fig. 2B). Fusarium populations in Bozeman and Huntley noninoculated stubble residues were not significantly different from each other over time. There was no significant change in 
Fusarium populations observed for the other three residue fractions with populations ranging from 0 to 300 copies. None of the residue bags or stubble samples analyzed showed signs of qPCR inhibition based on Mjba-1 qPCR results (data not shown).

Spring wheat residue decomposition. Stubble at Huntley was standing throughout the experiment. On the crowns of the stubble white mycelium was increasingly observed over the course of the experiment and the stubble became fragile during the last two collection times. In Bozeman, stubble was standing until the second winter, after which approximately $90 \%$ of the stubble was flattened by snow pack. White fungal growth was also observed on the crowns of the Bozeman stubble, which was also delicate near the end of the experiment. Black molds were not dominant on the stubble at either location but where frequently observed on the bagged residues.

Before residue samples were processed for DNA analysis, they were weighed to determine their percent weight relative to initial weight. These percent weights, as a measure of decomposition, were compared by location, residue fraction, and cultivar over the duration of the trial. The weight of the inoculated stubble and
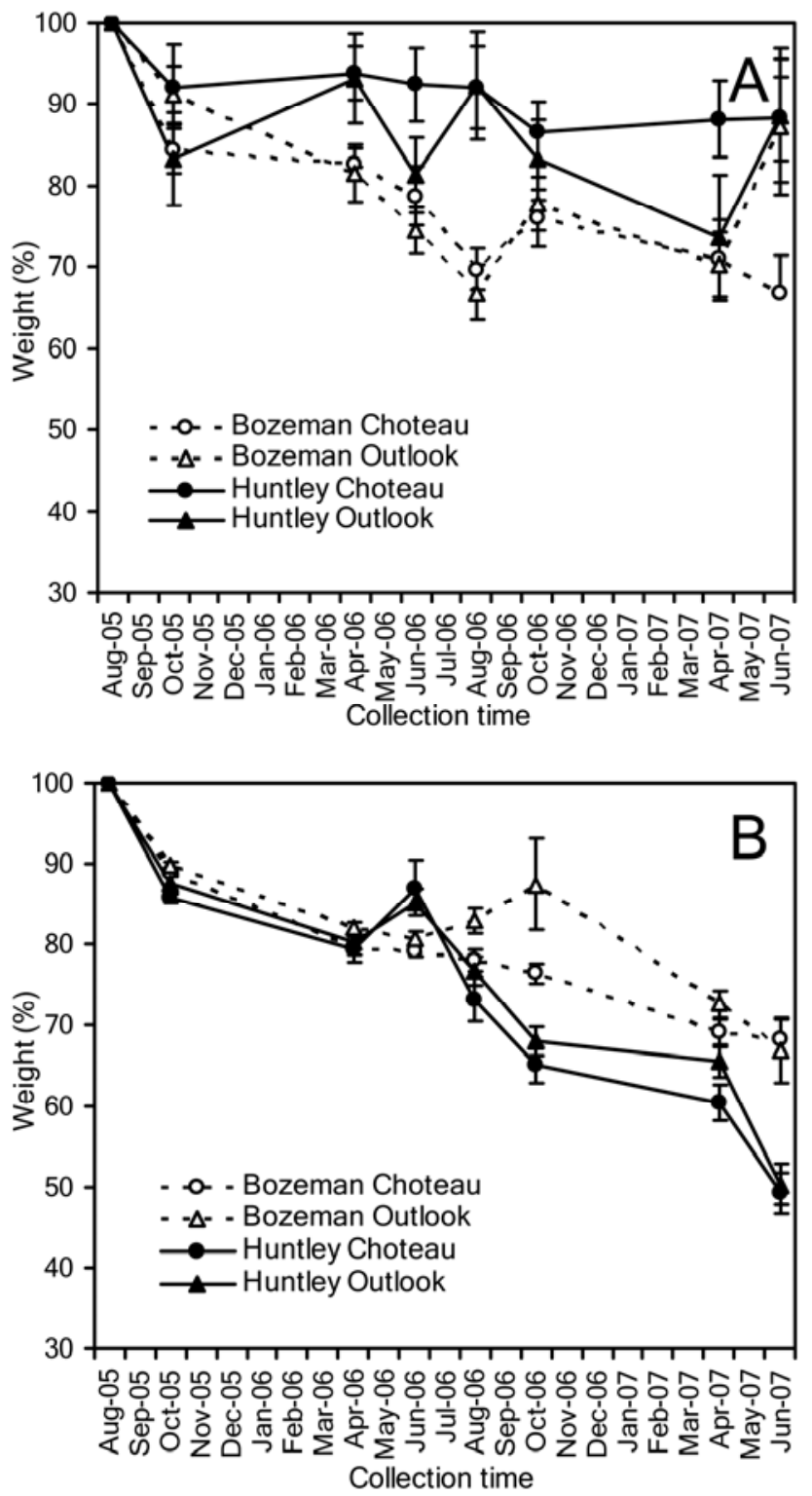

bagged residue significantly declined over time at both locations for all four residue fractions $(P<0.0001)$ (Fig. 3). There was no significant difference in weight loss between the two cultivars over time. In the Bozeman inoculated plots, the Choteau middle stem fractions lost significantly more weight than the Outlook middle stem fractions over time $(P=0.0036)$ (Fig. 3). In the Huntley inoculated plots, Choteau stubble lost significantly less weight than Outlook stubble over time $(P=0.0419)$ (Fig. 3). All four residue fractions lost significantly more weight at Huntley compared with Bozeman for inoculated plots (stubble $P<0.0001$; lower $P=0.0002$; middle $P<0.0001$; and chaff $P<0.0001$ ) (Fig. 3).

Similar results were obtained for the noninoculated plots except that there was a significant difference in weight loss between the two cultivars over time $(P=0.0011)$ (Fig. 4). Across locations, Choteau lost significantly more weight than Outlook for only the middle stem fraction over time $(P=0.0022)$ (Fig. 4). Choteau middle stem residues lost significantly more weight compared with Outlook middle stem residues in Bozeman over time $(P<$ $0.0001)$, as did Choteau stubble residues $(P=0.0122)$ (Fig. 4). No such differences were observed between cultivars in samples from
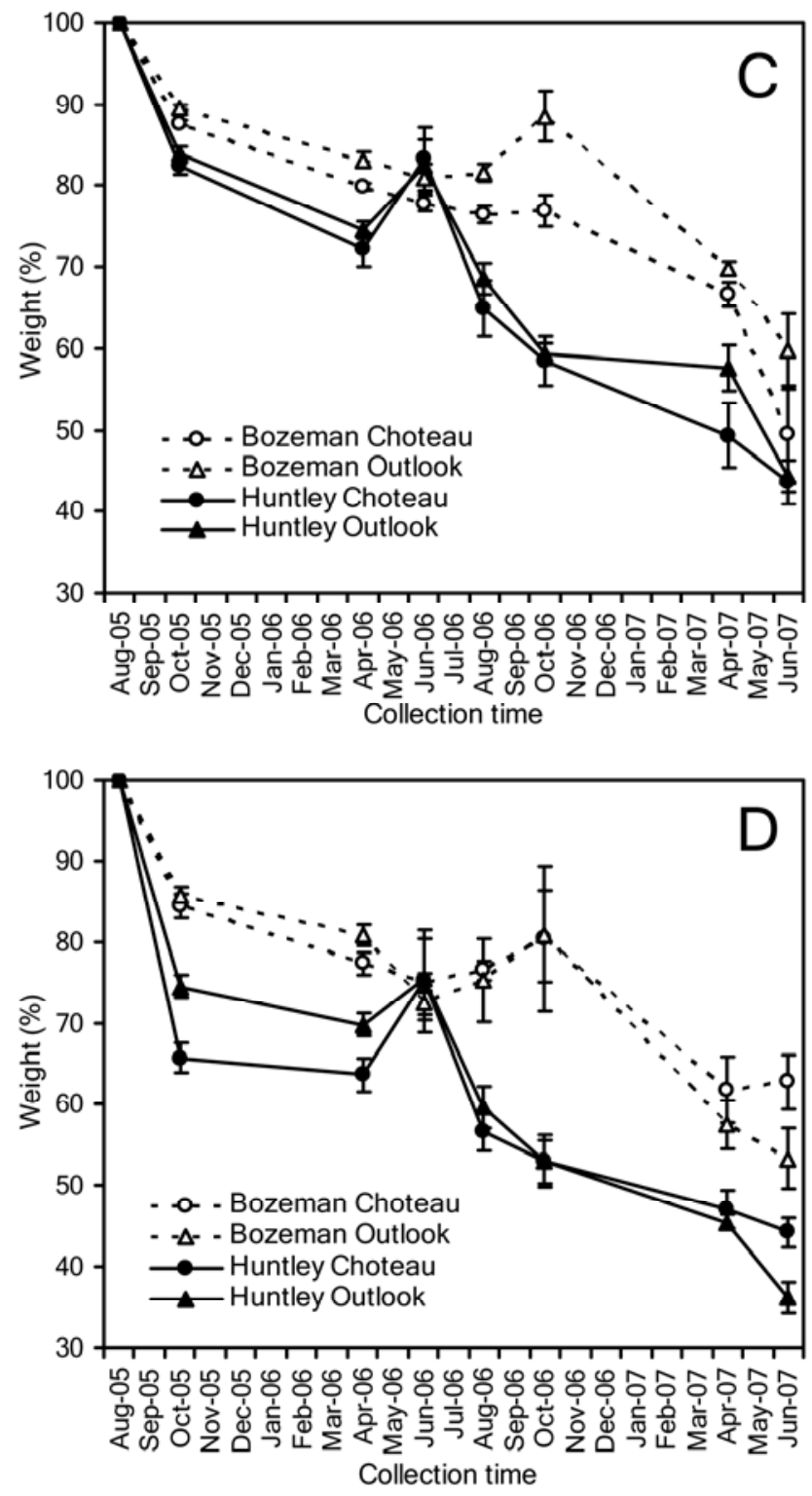

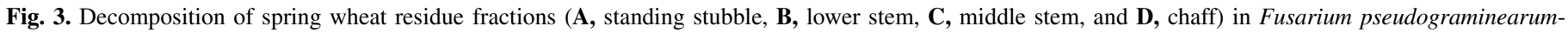

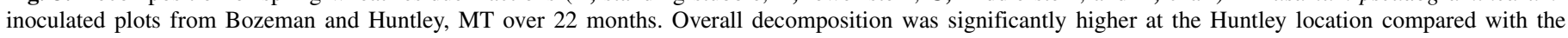
Bozeman location $(P \leq 0.0002)$. Weight means are a percentage of initial weight from six replicates with bars representing standard errors. 
the Huntley noninoculated plots. In the noninoculated plots, all four residue fractions lost significantly more weight at Huntley compared with Bozeman $(P<0.0001)$ (Fig. 4).

At the Huntley location, the inoculated stubble samples lost the least weight followed by the lower stem, middle stem and chaff residue fractions (Table 1). For Bozeman, the inoculated lower stem lost the least weight followed by the stubble, middle stem, and chaff residue fractions (Table 1). The same trends were observed in the noninoculated plots (Table 2).

Disease evaluations and Fusarium populations in reseeded spring wheat plots. In 2007, plots were reseeded without added inoculum and disease evaluations were carried out prior to harvest. Fusarium populations in inoculated plots were statistically similar in Huntley (mean $=21,192$ copies) and Bozeman (mean $=4,496$ copies). There was also no difference in Fusarium populations between Huntley (mean $=22$ copies) and Bozeman (mean $=55$ copies) noninoculated plots. No significant difference was observed in Fusarium populations between Choteau and Outlook for either inoculated or noninoculated plots. Fusarium populations in stubble from Bozeman (4,496 copies versus $101,733$ copies; $P=0.0002)$ and Huntley $(21,192$ copies versus
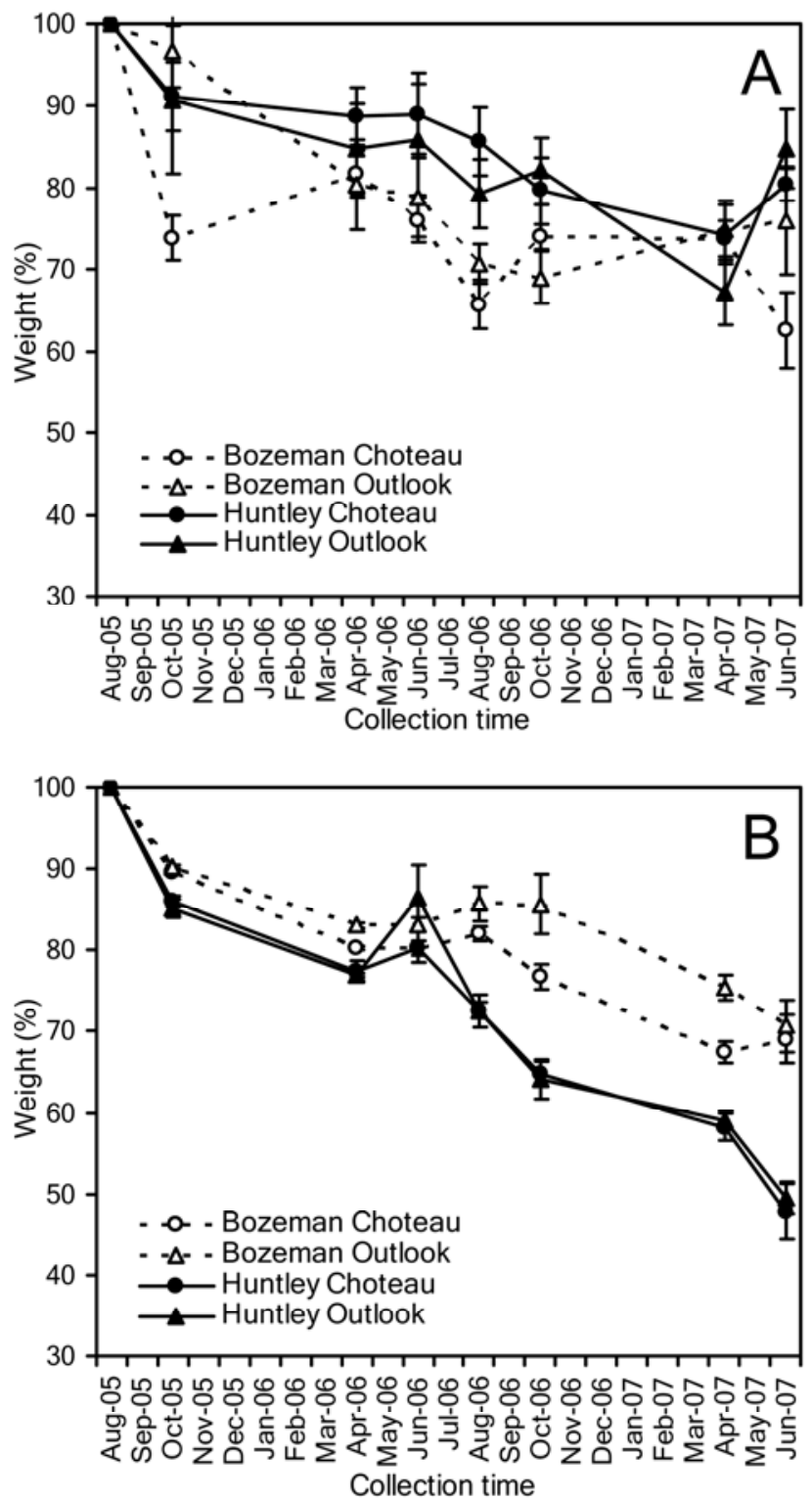

359,312; $P<0.0001)$ inoculated plots were significantly lower in the 2007 crop compared with the 2005 crop. Inoculated plots in Huntley (47.9) had a higher DSI than those in Bozeman (39.2) $(P=0.0343)$. Noninoculated plots in Huntley had significantly higher DSI than those at Bozeman (40.4 versus 34.5, respectively; $P=0.0030)$. For the noninoculated plots, Choteau (41.9) had a higher DSI compared with Outlook (33.1) $(P<0.0001)$, while there was no difference between the two in the inoculated plots (44.5 and 42.6, respectively). There was no difference between Bozeman and Huntley in the percent type-4 tillers for inoculated (2.3 and $9.8 \%$, respectively) and noninoculated plots (2.4 and $6.3 \%$, respectively). There was also no difference between the two cultivars in the percent type-4 tillers for inoculated or noninoculated plots.

Fusarium populations were related to the percent type-4 stems for both Bozeman $\left(r^{2}=0.66 ; P=0.0014\right)$ and Huntley $\left(r^{2}=0.59\right.$; $P=0.0032$ ) inoculated plots based on regression. DSI also related to Fusarium populations in Bozeman $\left(r^{2}=0.48 ; P=0.0128\right)$ and Huntley $\left(r^{2}=0.66 ; P=0.0013\right)$ inoculated plots. In the noninoculated plots, regression analysis between Fusarium populations and visual disease assessments were not made due to the
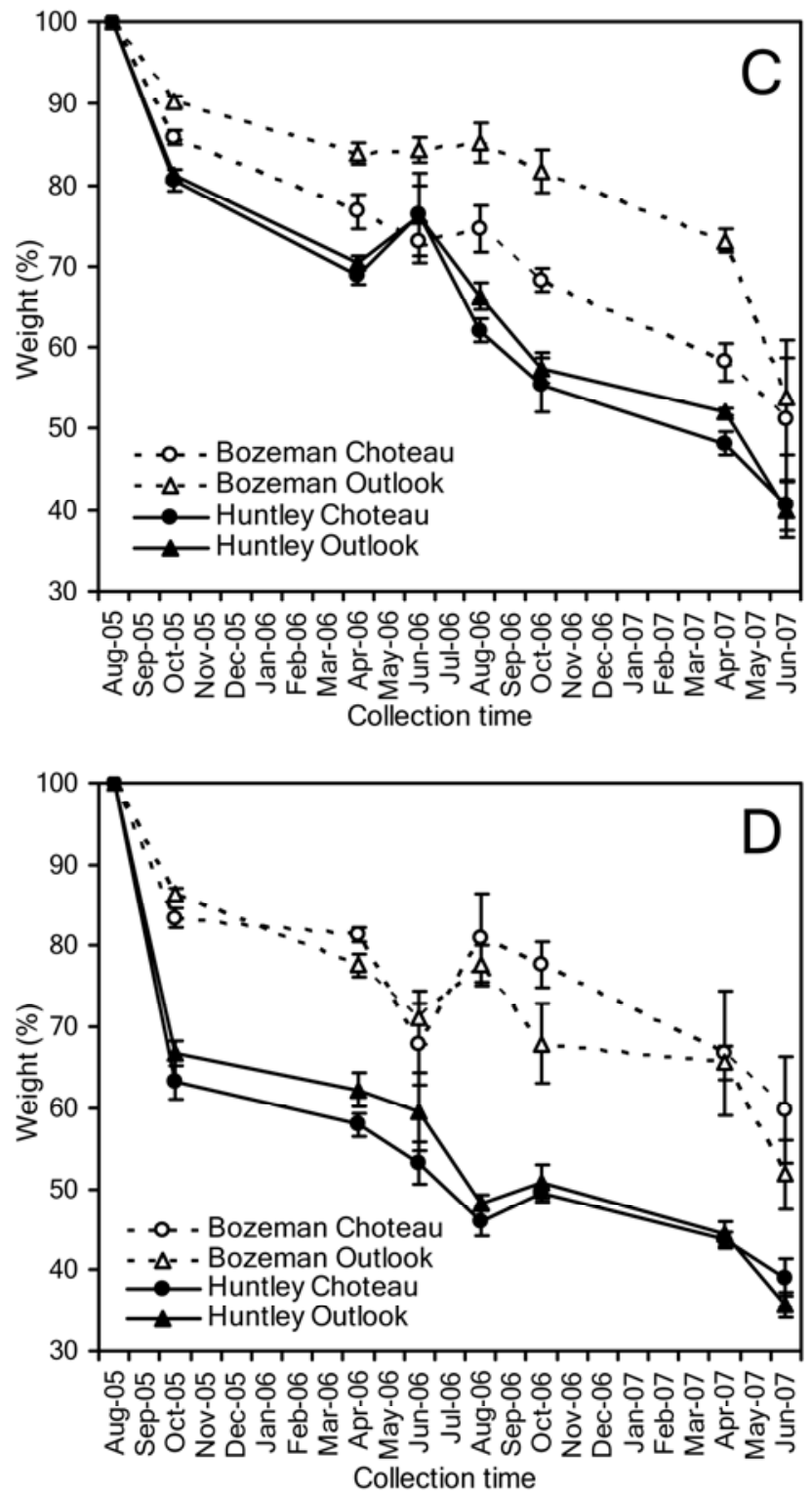

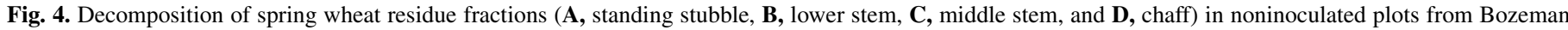

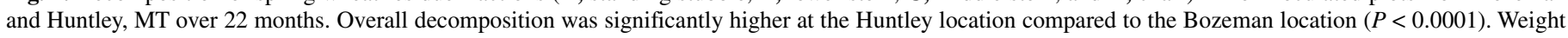
means are a percentage of initial weight from six replicates with bars representing standard errors. 
lack of ample disease. Fusarium populations in stubble residue sampled in April 2007 was significantly related with detected Fusarium populations in the reseeded crop for the inoculated $\left(r^{2}=\right.$ $0.44 ; P=0.0212)$ and noninoculated plots $\left(r^{2}=0.83 ; P<0.0001\right)$ in Bozeman based on regression. In Huntley, there was no relationship between Fusarium populations in April 2007 stubble residue and those quantified in reseeded plots for either inoculated or noninoculated plots. There were no significant differences between 2005 and 2007 Fusarium populations in stubble from the noninoculated plots at Bozeman or Huntley. None of the 2007 stubble samples analyzed showed signs of qPCR inhibition based on Mjba-1 qPCR results (data not shown).

\section{DISCUSSION}

Results from both the Huntley and Bozeman locations indicated two distinct phases of population dynamics for the FCR complex in spring wheat stubble residues as determined by qPCR. In the first phase, there was a rapid decline in Fusarium populations that occurred after plant senescence and lasted from August 2005 until at least October 2005 but not after April 2006. During this period, there was a 20 to 50 fold decline in copy numbers detected in stubble tissues. The mechanism that led to this decline was uncertain and was not determined in this work. When the populations stabilized was unclear due to the stubble becoming frozen in situ and unavailable for sampling in the period between October 2005 and April 2006. The second phase of population dynamics was one of relative stability. In this phase, Fusarium populations remained stable relative to amount of residue present. This stable phase lasted from April 2006 through the end of the experiment in June 2007. From the amplification, cloning and sequencing of fungal internal transcribed spacer regions from DNA samples taken at these times, it was observed that populations of saprophytic fungi were large relative to $\mathrm{Fu}$ sarium populations (data not shown). This observation has been noted in other studies as well (28). It suggests that resources are available in the stubble for active fungal growth, but that for whatever the reason, FCR species were unable to capitalize on them. Previous in vitro studies have suggested that $F$. culmorum is an effective saprophyte over a wide range of moisture levels (12), while other work has shown that $F$. pseudograminearum is ecologically limited to narrower moisture ranges by saprophytic competitors $(6,23)$.

Others have suggested that certain FCR species are capable of aggressively colonizing and decomposing wheat residues $(32,43)$. Given the increasing crop residue levels associated with no-till production in Montana, saprophytic colonization of wheat residues by FCR species is a significant concern. For that reason, considerable efforts were dedicated by this study to monitoring FCR species in the noninoculated and nonstubble (lower stem, middle stem and chaff) residue fractions. From monitoring these

TABLE 1. Weight for residue fractions in spring wheat plots inoculated with Fusarium pseudograminearum at Bozeman and Huntley, MT

\begin{tabular}{llc}
\hline Location & Residue $^{\mathrm{y}}$ & Weight $(\%)^{\mathrm{z}}$ \\
\hline Huntley & Stubble & $89.31 \mathrm{a}$ \\
Bozeman & Lower & $81.33 \mathrm{~b}$ \\
Bozeman & Stubble & $79.90 \mathrm{~b}$ \\
Bozeman & Middle & $79.26 \mathrm{bc}$ \\
Bozeman & Chaff & $76.48 \mathrm{~cd}$ \\
Huntley & Lower & $75.83 \mathrm{~d}$ \\
Huntley & Middle & $70.29 \mathrm{e}$ \\
Huntley & Chaff & $63.71 \mathrm{f}$ \\
\hline
\end{tabular}

y Stubble $=0$ to $20 \mathrm{~cm}$ above soil surface, lower stem $=20$ to $38 \mathrm{~cm}$, middle stem $=38$ to $66 \mathrm{~cm}$, and chaff $=$ floral parts.

${ }^{\mathrm{z}}$ Means are a percentage of the initial weight. Least squared means of six replicates were separated in PROC MIXED using the pmix800 macro. Means followed by different letters are significantly different at $\alpha=0.05$. fractions over two locations and 22 months of this study, there was no significant saprophytic colonization of residues by detectable members of the FCR complex as Fusarium populations remained low throughout. Thus, residue fractions, if not colonized pathogenically, do not appear to act as a resource base for population expansion.

Another concern for Montana's growers has been the wide adoption of solid stem wheat. Solid stemmed wheat cultivars are adopted to combat wheat stem sawfly in the infested regions of the Northern Great Plains. These cultivars have solid pith with a high carbon to nitrogen ratio (18). Concern has mounted that due to higher carbon to nitrogen ratios or some other physical or compositional differences between solid and hollow stems that the adoption of solid stems would enhance FCR species survival during noncropping periods. The results from this study showed that Fusarium populations in the solid stem spring wheat cultivar, Choteau, behaved in patterns similar to those in the hollow stem cultivar, Outlook. Therefore there is no evidence that solid stems act as better reservoirs for FCR species through noncropping cycles.

In 2007, the middle four rows of plots were reseeded and Fusarium populations in new stubble were measured. The 2007 populations were about 5\% of the populations observed in 2005. From comparisons with qPCR analysis of initial inoculum, the populations remaining in the stubble portions following the fallow period were much smaller than those used in the initial inoculations (data not shown). For inoculated trials conducted in Bozeman and Huntley in 2007, FCR severities overall were low. This suggests that the low Fusarium populations obtained in the re-seeded plots were not only the result of lower inoculum loads but probably also less conducive environmental conditions. Studies by others have shown that FCR development is the result of high spring moisture followed by low late season moisture. Bottlenecks in either spring or late season conditions can dramatically effect disease development $(4,6)$. This appears to be the case for this study in 2007 as there was little early season moisture and plenty of late season moisture.

For the Western United States, FCR is more severe in annual cropping systems than wheat-fallow systems (36). In this study, the Fusarium populations in remaining residues measured from 8 to 22 months postharvest were similar to each other. In addition, decomposition of stubble residue was minimal during this time. These observations suggest differences in disease levels between cropping systems may involve critical issues not addressed by this study including but not limited to soil water recharge and the physiological health of Fusarium populations over time.

For simplicity of description, the pathogen populations monitored by qPCR in this study were designated as Fusarium populations as per the assay's specificity. However, given that Fusarium populations were 100 -fold greater in the inoculated plots versus the noninoculated plots and that F. pseudo-

TABLE 2. Weight for residue fractions in noninoculated spring wheat plots at Bozeman and Huntley, MT

\begin{tabular}{llc}
\hline Location & Residue $^{\mathrm{y}}$ & Weight $(\%)^{\mathrm{z}}$ \\
\hline Huntley & Stubble & $85.25 \mathrm{a}$ \\
Bozeman & Lower & $82.44 \mathrm{~b}$ \\
Bozeman & Stubble & $78.39 \mathrm{c}$ \\
Bozeman & Middle & $77.52 \mathrm{c}$ \\
Bozeman & Chaff & $75.99 \mathrm{~cd}$ \\
Huntley & Lower & $73.81 \mathrm{~d}$ \\
Huntley & Middle & $67.23 \mathrm{e}$ \\
Huntley & Chaff & $57.49 \mathrm{f}$ \\
\hline
\end{tabular}

y Stubble $=0$ to $20 \mathrm{~cm}$ above soil surface, lower stem $=20$ to $38 \mathrm{~cm}$, middle stem $=38$ to $66 \mathrm{~cm}$, and chaff $=$ floral parts.

${ }^{\mathrm{z}}$ Means are a percentage of the initial weight. Least squared means of six replicates were separated in PROC MIXED using the pmix800 macro. Means followed by different letters are significantly different at $\alpha=0.05$. 
graminearum was the only one of the three FCR species isolated from wheat residues, the population dynamics being described were likely dominated by the single isolate of $F$. pseudograminearum with which the plots were inoculated. Other researchers have shown considerable phenotypic variability between and within species of the FCR complex that has not been taken into consideration by this study $(25,37)$.

In conclusion, Fusarium populations in this study displayed two distinct phases. In the first phase, there was a rapid decline in populations. This decline was completed by spring of the following year. In the second phase, Fusarium populations persisted at modest levels that were relatively stable in relationship to residue mass. This phase lasted at least 18 months, well into the recrop cycle of a wheat-fallow system. Because Fusarium populations remained relatively stable, the higher disease severity experienced under annual no-till recrop systems may relate to other dynamics including moisture stress brought about by a more intense production system, the physiological weakening of the remaining Fusarium populations, other isolates that may display different population dynamics, and the composition of the local microflora. Finally, colonization of uninfested residues by detectable FCR species was not observed during this trial. The results presented here come from the analysis of 1,536 samples and provide insights into FCR species survival in a semiarid environment that was previously unknown. Future research is needed to document the physiological status of FCR species during the two phases of its survival in stubble residue, the interactions between FCR species and other native saprophytes, and the dynamics of residue populations during cropping periods.

\section{ACKNOWLEDGMENTS}

This project was supported by the National Research Initiative of the United States Department of Agriculture Cooperative State Research, Education and Extension Service grant number 2005-35319-16193 and by the Montana Agriculture Experiment Station.

\section{LITERATURE CITED}

1. Backhouse, D., Abubakar, A. A., Burgess, L. W., Dennis, J. I., Holloway, G. J., Wildermuth, G. B., Wallwork, J., and Henry, F. J. 2004. Survey of Fusarium species associated with crown rot of wheat and barley in eastern Australia. Aust. Plant Pathol. 33:255-261.

2. Bailey, K. L. 1996. Diseases under conservation tillage systems. Can. J. Plant Sci. 76:635-639.

3. Bailey, K. L., Mortensen, K., Lafond, G. P., Watson, P. R., and Derksen, D. A. 2001. Effect of tillage and crop rotation on root and foliar diseases of wheat and pea in Saskatchewan from 1991-1998: Univariate and multivariate analyses. Can. J. Plant Sci. 81:789-803.

4. Bateman, G. L., and Murray, G. 2001. Seasonal variations in populations of Fusarium species in wheat-field soil. Appl. Soil Ecol. 18:117-128.

5. Bluhm, B. H., Cousins, M. A., and Woloshuk, C. P. 2004. Multiplex realtime PCR detection of fumonisin-producing and trichothecene-producing groups of Fusarium species. J. Food Prot. 76:536-543.

6. Burgess, L. W., Backhouse, D., Summerell, B. A., and Swan, L. J. 2001. Crown rot of wheat. Pages 271-294 in: Fusarium: Paul E. Nelson Memorial Symposium. American Phytopathological Society, St. Paul, $\mathrm{MN}$.

7. Cook, R. J. 1980. Fusarium foot rot of wheat and its control in the Pacific Northwest. Plant Dis. 64:1061-1066.

8. Cook, R. J. 1981. Fusarium diseases of wheat and other small grains in North America. Pages 39-52 in: Fusarium: Diseases, Biology and Taxonomy. The Pennsylvania State University Press, University Park.

9. Dodman, R. L., and Wildermuth, G. B. 1989. The effect of stubble retention and tillage practices in wheat and barley on crown rot caused by Fusarium pseudograminearum. Plant Prot. Q. 4:98-99.

10. Fernandez, M. R., Zentner, R. P., DePauw, R. M., Gehl, D., and Stevenson, F. C. 2007. Impacts of crop production factors on common root rot of barley in Eastern Saskatchewan. Crop Sci. 47:1585-1595.

11. Gao, X., Jackson, T. A., Lambert, K. N., Li, S., Hartman, G. L., and Niblack, T. L. 2004. Detection and quantification of Fusarium solani $\mathrm{f}$. sp. glycines in soybean roots with real-time quantitative polymerase chain reaction. Plant Dis. 88:1372-1380.
12. Garrett, S. D. 1975. Cellulolysis rate and competitive saprophytic colonization of wheat straw by foot rot fungi. Soil Biol. Biochem. 7:323327.

13. Halstensen, A. S., Nordby, K. C., Eduard, W., and Klemsdal, S. S. 2006. Real-time PCR detection of toxigenic Fusarium in airborne and settled grain dust and associations with trichothecene mycotoxins. J. Environ. Monit. 8:1235-1241.

14. Hill, J. P., Fernandez, J. A., and McShane, M. S. 1983. Fungi associated with common root rot of winter wheat in Colorado and Wyoming. Plant Dis. 67:795-797.

15. Hogg, A. C., Johnston, R. H., and Dyer, A. T. 2007. Applying real-time quantitative PCR to Fusarium crown rot of wheat. Plant Dis. 91:10211028.

16. Inch, S. A., and Gilbert, J. 2003. Survival of Gibberella zeae in Fusariumdamaged wheat kernels. Plant Dis. 87:282-287.

17. Kane, R. T., Smiley, R. W., and Sorrels, M. E. 1987. Relative pathogenicity of select Fusarium species and Microdochium bolleyi to winter wheat in New York. Plant Dis. 71:177-181.

18. Kasting, R., and McGinnis, A. J. 1961. Comparison of tissues from solidand hollow-stemmed spring wheats during growth. Can. J. Zool. 39:273280.

19. Khonga, E. B., and Sutton, J. C. 1988. Inoculum production and survival of Gibberella zeae in maize and wheat residues. Can. J. Plant Pathol. 10:232-239.

20. Köhl, J., de Hass, B. H., Kastelein, K., Burgers, S. L. G. E., and Waalwijk, C. 2007. Population dynamics of Fusarium spp. and Microdochium nivale in crops and crop residues of winter wheat. Phytopathology 97:971-978.

21. Lanning, S. P., Carlson, G. R., Nash, D., Wichman, D. M., Kephart, K., Stougaard, R. N., Kushnak, G. D., Eckhoff, J. L., Grey, W. E., and Talbert, L. E. 2004. Registration of 'Choteau' Wheat. Crop Sci. 44:2263-2264.

22. Lanning, S. P., Habernicht, D., Wichman, D. M., Kephart, K. D., Stougaard, R. N., Kushnak, G. D., Eckhoff, J. L., Carlson, G. R., Grey, W. E., and Talbert, L. E. 2003. Registration of 'Outlook' wheat. Crop Sci. 43:2302-2303

23. Liddell, C. M., and Burgess, L. W. 1988. Wax partitioned soil columns to study the influence of soil moisture potential on the infection of wheat by Fusarium graminearum Group 1. Phytopathology 78:185-189.

24. Mathre, D. E., and Johnston, R. H. 1975. Cephalosporium stripe of winter wheat: Procedures for determining host response. Crop Sci. 15:591-594.

25. Miedaner, T., Cumagun, C. J. R., and Chakraborty, S. 2008. Population genetics of three important head blight pathogens, Fusarium graminearum, $F$. pseudograminearum, and $F$. culmorum. J. Phytopathology 156:129-139.

26. Painter, J. E., and Lambert, K. N. 2003. Meloidogyne javanica chorismate mutase transcript expression profile using real-time quantitative RT-PCR. J. Nematol. 35:82-87.

27. Paulitz, T. C. 2006. Low input no-till cereal production in the Pacific Northwest of the U.S.: The challenges of root diseases. Eur. J. Plant Pathol. 115:271-281

28. Pereyra, S. A., and Dill-Macky, R. 2004. Survival and inoculum production of Gibberella zeae in wheat residue. Plant Dis. 88:724-730.

29. Pereyra, S. A., and Dill-Macky, R. 2008. Colonization of the residue of diverse plant species by Gibberella zeae and their contribution to Fusarium head blight inoculum. Plant Dis. 92:800-807.

30. Pettitt, T., Xiangming, X., and Parry, D. 2003. Association of Fusarium species in the wheat stem rot complex. Eur. J. Plant Pathol. 109:769-774.

31. Reischer, G. H., Lemmens, M., Farnleitner, A., Adler, A., and Mach, R. L. 2004. Quantification of Fusarium graminearum in infected wheat by species specific real-time PCR applying a TaqMan probe. J. Microbiol. Meth. 59:141-146.

32. Sadasivan, T. R. S. 1939. Succession of fungi decomposing wheat straw in different soils, with a special reference to Fusarium culmorum. Ann. Biol. 26:497-508.

33. Saxton, A. M. 1998. A macro for converting mean separation output to letter groupings in Proc Mixed. Pages 1243-1246 in: Proc. 23rd SAS Users Group Intl., SAS Institute, Cary, NC.

34. Schnerr, H., Niessen, L., and Vogel, R. F. 2001. Real-time detection of the tri5 gene in Fusarium species by LightCycler-PCR using SYBR Green I for continuous fluorescence monitoring. Intl. J. Food Microbiol. 71:53-61.

35. Smiley, R. W., and Patterson, L. M. 1996. Pathogenic fungi associated with Fusarium foot rot of winter wheat in the semiarid Pacific Northwest. Plant Dis. 80:944-949.

36. Smiley, R. W., Collins, H. P., and Rasmussen, P. E. 1996. Diseases of wheat in long-term agronomic experiments at Pendleton, Oregon. Plant Dis. 80:813-820.

37. Smiley, R. W., Gourlie, J. A., Easley, S. A., and Patterson, L. M. 2005. Pathogenicity of fungi associated with the wheat crown rot complex in Oregon and Washington. Plant Dis. 89:949-957.

38. Smiley, R. W., Gourlie, J. A., Easley, S. A., Patterson, L. M., and Whittaker, R. G. 2005. Crop damage estimates for crown rot of wheat and 
barley in the Pacific Northwest. Plant Dis. 89:595-604.

39. Strausbaugh, C. A., Bradley, C. A., Koehn, A. C., and Forster, R. L. 2004. Survey of root diseases of wheat and barley in Southwestern Idaho. Can. J. Plant Pathol. 26:167-176.

40. Strausbaugh, C. A., Overturf, K., and Koehn, A. C. 2005. Pathogenicity and real-time PCR detection of Fusarium spp. in wheat and barley roots. Can. J. Plant Pathol. 27:430-438.

41. Waalwijk, C., Hiede, R., Vries, I., Lee, T., Schoen, C., Corainville, C.,
Häuser-Hahn, I., Kastelein, P., Köhl, J., Lonnet, P., Demarquet, T., and Kema, G. H. J. 2004. Quantitative detection of Fusarium species in wheat using Taqman. Eur. J. Plant Pathol. 110:481-494.

42. Wiese, M. V. 1987. Compendium of Wheat Diseases. 2nd ed. American Phytopathological Society, St. Paul, MN.

43. Willcock, J., and Magan, N. 2001. Impact of environmental factors on fungal respiration and dry matter losses in wheat straw. J. Stored Prod. Res. 37:35-45. 